\title{
Decabromodiphenyl Ether versus Decabromodiphenyl Ethane: Source, Fate, and Influencing Factors in a Coastal Sea Nearing Source Region
}

\author{
Xiaomei Zhen, Yanfang Li, Jianhui Tang,* Xinming Wang, Lin Liu, Mingyu Zhong, and Chongguo Tian \\ Cite This: Environ. Sci. Technol. 2021, 55, 7376-7385 \\ Read Online
}

ACCESS | Lill Metrics \& More | 回 Article Recommendations | (I) Supporting Information

ABSTRACT: Both decabromodiphenyl ether (BDE 209) and decabromodiphenyl ethane (DBDPE) are still produced in large quantities in China, especially in the Shandong Province closed to the Bohai Sea (BS). This study conducted a comprehensive investigation of the distribution and budget of brominated flame retardants (BFRs) in the BS. BDE 209 was the predominant $\mathrm{BFR}$ in most of the investigated rivers flowing into the $\mathrm{BS}$, although DBDPE exceeded BDE 209 in certain rivers as a result of the replacement of BDE 209 with DBDPE in North China. The spatial distributions of BFRs in the rivers were controlled by the proximity of the BFR manufacturing base and the extent of urbanization. BFRs' spatial distribution in the BS was influenced by a combination of land-based pollution sources, environmental parameters (e.g., suspended particulate matter, particulate organic carbon, and particulate black carbon), and

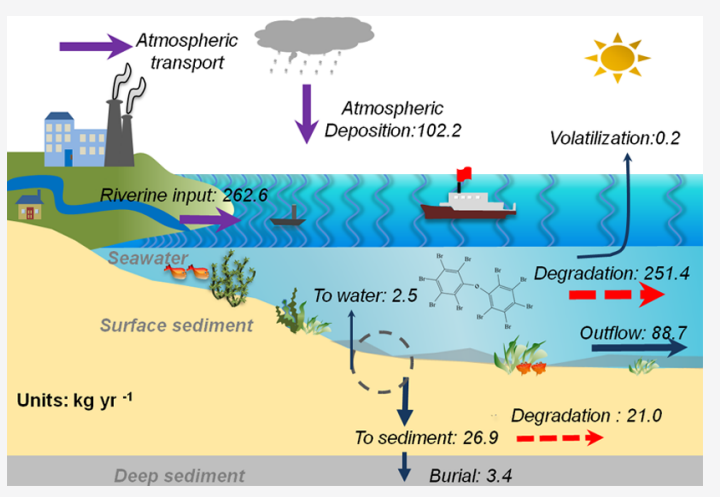
hydrodynamic conditions. The spatial variation trend of BDE 209/DBDPE ratios in various environmental media provided useful information. Vertically, the BDE 209/DBDPE ratio decreased from the seawater surface layer to the sediment, indicating their differential transport in the BS. A multi-box mass balance model and analysis of BDE 209 showed that degradation was the primary sink of BFRs in seawater $(\sim 68 \%)$ and surface sediment $(\sim 72 \%)$ in the BS. KEYWORDS: brominated flame retardants, source and sink, multi-box mass balance model, river discharge, atmospheric deposition, BDE 209/DBDPE ratio, Bohai Sea

\section{INTRODUCTION}

Brominated flame retardants (BFRs), which contain bromine atoms, are added to plastics, wires, cables, textiles, and electronics to reduce the flammability of these products. ${ }^{1-3}$ At least 75 chemicals are classified as BFRs. ${ }^{4}$ Among them, polybrominated diphenyl ethers (PBDEs) have been widely detected in various environments and were listed as persistent organic pollutants (POPs) in 2009 and 2017 under the Stockholm Convention. ${ }^{5}$ Some alternatives or novel BFRs (NBFRs), such as decabromodiphenyl ethane (DBDPE), pentabromoethylbenzene (PBEB), pentabromotoluene (PBT), 1,2-bis(2,4,6-tribromophenoxy) ethane (BTBPE), hexabromobenzene (HBB), 2-ethylhexyl,2,3,4,5-tetrabromobenzoate (EHTBB), and 2,3-dibromopropyl-2,4,6-tribromophenyl ether (DPTE), have been produced and widely used owing to the restrictions on the use of PBDEs. ${ }^{6,7}$ As a principal alternative for deca-BDE, DBDPE is structurally similar to BDE 209 and reached a production capacity of 11,000 tons in China in 2006. ${ }^{1}$ Numerous studies have detected BFRs in the air, soil, water, sediment, and biota. ${ }^{8-11}$

The coastal region is the most productive region in terms of preliminary production $^{12}$ and fishery resources ${ }^{13}$ but is also usually regarded as a major reservoir and sink for POPs. ${ }^{14,15}$
Generally, atmospheric deposition and riverine discharge are the two predominant input pathways for POPs to the sea. ${ }^{16-19}$ For instance, Wang et al. ${ }^{19}$ reported that 69 and $31 \%$ of annual PBDEs in the southern Yellow Sea were attributed to riverine discharge and atmospheric deposition, respectively. In addition, atmospheric deposition was a significant source of BFRs for the BS. ${ }^{20}$ However, little is known about the discharge of BFRs via rivers into the BS. Previous studies also calculated the budget of black carbon (BC) and polycyclic aromatic hydrocarbons (PAHs) by using a box model of the BS; however, these studies did not account for fate processes (e.g., degradation, diffusion, and resuspension). ${ }^{19,21}$ Instead, a multi-box mass balance model can be used to estimate the relative importance of various fate processes and compound concentration trends. ${ }^{22}$ Overall, studies of the BFR fluxes and

Received: December 17, 2020

Revised: April 29, 2021

Accepted: April 30, 2021

Published: May 17, 2021 


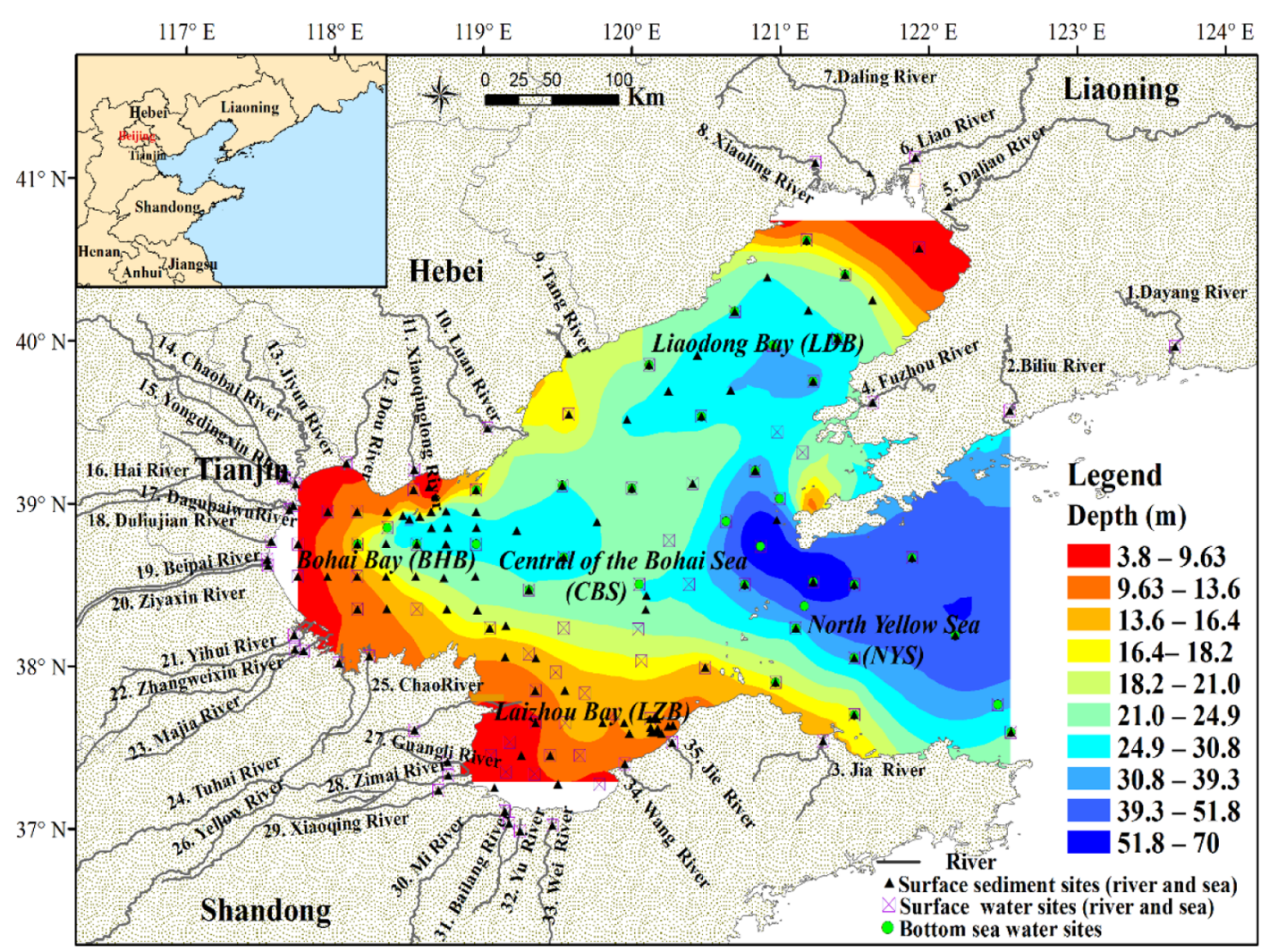

Figure 1. Map of sampling sites in the BS.

budget contribute significantly toward our understanding of the regional POP cycle.

The Bohai Sea (BS) is a semi-enclosed shallow marginal sea along the northern coast of China. The $\mathrm{BS}$ receives huge inputs of domestic sewage and industrial wastewater from the Tianjin metropolis and surrounding provinces (Liaoning, Hebei, and Shandong). ${ }^{17,23}$ More than 40 rivers discharge into the BS, with an approximate total annual discharge of 60 billion cubic meters of water that brings organic pollutants into the BS. ${ }^{17}$ The largest BFR manufacturing base in China is located around Laizhou Bay (LZB) in the BS, which results in high BFR levels in the atmosphere, water, and sediment in this region. ${ }^{1,24,25}$ However, a systematic and comprehensive survey of BFRs in the BS and its estuaries has not been conducted to date.

The present study has three major objectives: (1) to explore the concentrations, spatial patterns, and influencing factors of BFR concentrations in the BS and its river estuaries; (2) to determine and assess the BDE 209/DBDPE ratio in different environmental media; and (3) to quantify the sources and sinks of BFRs under a steady-state scenario based on a multibox model of the BS.

\section{MATERIALS AND METHOD}

2.1. Sampling. During 2013-2014, a total of 143 surface sediment samples (river and marine) were collected using a grab sampler or stainless-steel box corer. The sediment samples included 32 samples from rivers discharging into the BS, 3 samples from rivers discharging into the northern Yellow Sea (NYS), 96 samples from the BS, and 12 samples from the NYS (Figure 1). All sediments were wrapped in precombusted aluminum foil and then kept in a refrigerator at $-20{ }^{\circ} \mathrm{C}$ prior to extraction.
In addition, a total of 138 water samples were collected, and the water samples included 33 surface river water (freshwater) samples (30 rivers discharging into the BS and 3 rivers discharging into the NYS), 69 surface seawater samples, and 35 bottom seawater samples (Figure 1). All surface seawater samples were collected by hand using a stainless-steel barrel at about $5 \mathrm{~cm}$ below the water surface. Meanwhile, bottom seawater samples were collected using a Van Dorn sampler about $2 \mathrm{~m}$ above the bottom sediment. Water samples were stored in a $50 \mathrm{~L}$ stainless-steel barrel and then pumped through a glass fiber filter $(0.7 \mu \mathrm{m}$, Whatman $)$ housed in a stainless steel holder to trap particulates and through an Amberlite XAD-2 resin glass column for the dissolved phase within $24 \mathrm{~h}$ of sampling. ${ }^{26,27}$ Filters and columns were stored at -20 and 4 ${ }^{\circ} \mathrm{C}$, respectively, until extraction. The sampling method was the same as that in our previous studies. ${ }^{11,24}$

2.2. Extraction and Analysis. Extraction and analysis were based on methods used in previous studies. ${ }^{6,24}$ All samples were spiked with $10 \mathrm{ng}$ of hexabromobenzene $\left({ }^{13} \mathrm{C}\right.$ $\mathrm{HBB}$ ) and $20 \mathrm{ng}$ of polychlorinated biphenyl (PCB 209) as surrogate standards before extraction. Filters and sediments were Soxhlet-extracted using dichloromethane (DCM) for 24 $\mathrm{h}$, and water columns were extracted in a modified Soxhlet apparatus with DCM for $24 \mathrm{~h}$. After extraction, the extracts were concentrated to $\sim 2 \mathrm{~mL}$, and the solvent was then exchanged with hexane (HEX). In short, all concentrated extracts were further cleaned in a $2.5 \mathrm{~g}$ silica column $(10 \%$ water deactivated) over $3 \mathrm{~g}$ of anhydrous sodium sulfate. All columns were eluted with $20 \mathrm{~mL}$ of HEX and then concentrated to $\sim 50 \mu \mathrm{L}$. Before analysis, $20 \mathrm{ng}$ of PCB 208 (AccuStandard) was added to each sample as an injection standard. 
Table 1. Range and Mean BFR Concentrations in Water (Dissolved and Particulate Phases) and Sediment Samples ${ }^{a}$

\begin{tabular}{|c|c|c|c|c|c|c|c|c|c|}
\hline \multirow[b]{2}{*}{ compounds } & & \multicolumn{3}{|c|}{ dissolved phase $\left(\mathrm{ng} \mathrm{L}^{-1}\right)$} & \multicolumn{3}{|c|}{ particulate phase $\left(\mathrm{ng} \mathrm{L}^{-1}\right)$} & \multicolumn{2}{|c|}{ sediment ( $\left.\mathrm{ng} \mathrm{g}^{-1} \mathrm{dw}\right)$} \\
\hline & & freshwater & surface sea & bottom sea & freshwater & surface sea & bottom sea & river & marine \\
\hline \multirow[t]{2}{*}{ BDE 209} & range & n.d. to 0.61 & n.d. to 0.093 & n.d. to 0.18 & $0.052-501$ & n.d. to 11.3 & n.d. to 0.94 & n.d. to 274 & n.d. to 17.7 \\
\hline & mean & $0.040 \pm 0.11$ & $0.010 \pm 0.033$ & $0.006 \pm 0.02$ & $18.3 \pm 85.6$ & $0.42 \pm 0.61$ & $0.23 \pm 0.19$ & $11.1 \pm 45.4$ & $2.56 \pm 3.04$ \\
\hline \multirow[t]{2}{*}{$\sum_{7} \mathrm{PBDEs}$} & range & n.d. to 1.50 & n.d. to 0.004 & n.d. to 0.020 & $0.0002-17.8$ & n.d. to 0.089 & n.d. to 0.031 & $0.001-4.00$ & n.d. to 1.84 \\
\hline & mean & $0.056 \pm 0.28$ & $0.001 \pm 0.003$ & $0.0002 \pm 0.001$ & $0.59 \pm 3.05$ & $0.007 \pm 0.013$ & $0.018 \pm 0.006$ & $0.16 \pm 0.66$ & $0.015 \pm 0.031$ \\
\hline \multirow[t]{2}{*}{ DBDPE } & range & n.d. to 0.16 & n.d. to 0.052 & n.d. to 0.11 & $0.048-14.4$ & n.d. to 1.45 & n.d. to 0.33 & $0.18-203$ & n.d. to 11.2 \\
\hline & mean & $0.009 \pm 0.030$ & $0.004 \pm 0.019$ & $0.002 \pm 0.008$ & $1.88 \pm 3.62$ & $0.15 \pm 0.23$ & $0.085 \pm 0.074$ & $14.1 \pm 35.6$ & $2.74 \pm 2.65$ \\
\hline \multirow[t]{2}{*}{$\sum_{4}$ NBFRs } & range & n.d. to 0.034 & n.d. to 0.014 & n.d. to 0.052 & $0.0001-3.48$ & n.d. to 0.019 & n.d. to 0.025 & $0.001-3.25$ & n.d. to 0.23 \\
\hline & mean & $0.003 \pm 0.007$ & $0.002 \pm 0.009$ & $0.0002 \pm 0.002$ & $0.20 \pm 0.74$ & $0.002 \pm 0.003$ & $0.018 \pm 0.005$ & $0.14 \pm 0.54$ & $0.033 \pm 0.044$ \\
\hline \multirow[t]{2}{*}{$\sum$ BFRs } & range & $0.001-1.54$ & n.d. to 0.26 & n.d. to 0.16 & $0.15-530$ & n.d. to 11.5 & n.d. to 1.22 & $0.19-483$ & $5.08 \pm 5.50$ \\
\hline & mean & $0.11 \pm 0.31$ & $0.017 \pm 0.056$ & $0.009 \pm 0.028$ & $21.0 \pm 90.1$ & $0.71 \pm 1.52$ & $0.30 \pm 0.25$ & $25.5 \pm 81.3$ & $0.007 \pm 29.3$ \\
\hline
\end{tabular}

${ }^{a} \sum_{7}$ PBDEs: sum of BDE 28, 47, 99, 100, 153, 154, and 183; $\sum_{4}$ NBFRs: sum of PBT, PBEB, HBB, and BTBPE; $\sum$ BFRs: sum of BDE 209, $\sum_{7}$ PBDEs, DBDPE, and $\sum_{4}$ NBFRs.

Seven NBFRs (i.e., PBT, PBEB, DPTE, HBB, EHTBB, BTBPE, and DBDPE) and eight PBDE congeners (BDE 28, BDE 47, BDE 99, BDE 100, BDE 153, BDE 154, BDE 183, and BDE 209) were purchased from Wellington Laboratories. All BFRs were measured using an Agilent $7890 \mathrm{~A}$ gas chromatograph coupled to an Agilent 5975C mass spectrometer (GC-MS) in an electron capture negative-ion chemical ionization mode with a DB-5HT $(15 \mathrm{~m}, 0.25 \mathrm{~mm}, 0.1 \mu \mathrm{m}$, Agilent) capillary column. The quantification method was based on our previous studies. ${ }^{11,24}$ The oven program was set as follows: an initial temperature of $80{ }^{\circ} \mathrm{C}$ held for $2 \mathrm{~min}$ before being increased at a rate of $10{ }^{\circ} \mathrm{C} \mathrm{min}-1$ to (i) $200{ }^{\circ} \mathrm{C}$ (held for $5 \mathrm{~min}$ ), (ii) $260^{\circ} \mathrm{C}$ (held for $5 \mathrm{~min}$ ), and (iii) $310^{\circ} \mathrm{C}$ (held for $5 \mathrm{~min}$ ). The transfer line and injector temperatures were 310 and $280{ }^{\circ} \mathrm{C}$, respectively.

2.3. Quality Assurance and Quality Control. All glassware was baked for $5 \mathrm{~h}$ at $450{ }^{\circ} \mathrm{C}$ and then rinsed with DCM prior to use. The DCM used in this study was distilled. HEX and acetone were purchased from Merck (Germany). Laboratory blanks were monitored throughout the sampling and analysis. In sediments, the recoveries of ${ }^{3} \mathrm{C}-\mathrm{HBB}$ and PCB 209 were $69 \pm 14$ and $73 \pm 15 \%$, respectively. In water filters, their recoveries were $109 \pm 45$ and $106 \pm 43 \%$, respectively. In water columns, their recoveries were $92 \pm 33$ and $88 \pm 29 \%$, respectively. The method detection limits (MDLs) were calculated based on mean-field/lab blank values plus 3 standard deviations of the blanks. The MDLs of the sediments for individual PBDEs and individual NBFRs ranged from 0.002 $\mathrm{ng} \mathrm{g}^{-1}$ (dry weight, $\mathrm{dw}$ ) to $0.013 \mathrm{ng} \mathrm{g}^{-1} \mathrm{dw}$ and from $0.008 \mathrm{ng}$ $\mathrm{g}^{-1} \mathrm{dw}$ to $0.16 \mathrm{ng} \mathrm{g}^{-1} \mathrm{dw}$, respectively. The MDLs of the filters for individual PBDEs and individual NBFRs ranged from 0.0007 to $0.021 \mathrm{ng} \mathrm{L}^{-1}$ and from 0.0003 to $0.022 \mathrm{ng} \mathrm{L}^{-1}$, respectively. Finally, the MDLs of the columns for individual PBDEs and individual NBFRs ranged from 0.0007 to $0.021 \mathrm{ng}$ $\mathrm{L}^{-1}$ and from 0.0003 to $0.022 \mathrm{ng} \mathrm{L}^{-1}$, respectively.

In the following discussion, all data were not corrected for recoveries. If the values were below the MDLs, they were considered not detected (n.d.). However, flux calculations were based on $1 / 2$ MDLs for BFR concentrations below their MDLs. The $\sum_{7}$ PBDEs concentration represents the sum of BDE 28, BDE 47, BDE 99, BDE 100, BDE 153, BDE 154, and BDE 183, and the $\sum_{4}$ NBFRs concentration represents the sum of PBT, PBEB, HBB, and BTBPE. The $\sum$ BFRs concentration is the sum of $\sum_{7}$ PBDEs, BDE 209, $\sum_{4}$ NBFRs, and DBDPE. The concentrations of particulate organic carbon (POC) and particulate $\mathrm{BC}(\mathrm{PBC})$ in surface seawater were measured in our previous study. ${ }^{28}$ The samples for analyzing POC and PBC are the same batch as those for analyzing BFRs. The suspended particulate matter (SPM) concentration and total organic carbon (TOC) content were measured in this study. The detailed analytical methods of TOC and SPM are described in the Supporting Information (Text S1.1).

2.4. Multi-Box Mass Balance Model. The concentration trends and budgets of BFRs under a steady-state scenario were simulated using an improved multi-box mass balance model. ${ }^{22}$ This model included two input processes [riverine discharge $\left(E_{\mathrm{r}}\right)$ and atmospheric deposition $\left.\left(E_{\mathrm{a}}\right)\right]$ and seven output processes [volatilization $\left(k_{1}\right)$, outflow to the NYS $\left(k_{2}\right)$, degradation in water $\left(k_{3}\right)$, water to sediment transformation $\left(k_{4}\right)$, sediment to water transformation $\left(k_{5}\right)$, degradation in sediment $\left(k_{6}\right)$, and burial to deep sediment $\left.\left(k_{7}\right)\right]$. In the model, the inputs were kept constant and the concentration trends and budgets of BFRs were simulated under steady-state conditions. The amounts of BFRs in water $\left(M_{\mathrm{w}}, \mathrm{kg}\right)$ and sediment $\left(M_{\mathrm{s}}, \mathrm{kg}\right)$ can be expressed by eqs 1 and 2 , respectively.

$$
\begin{aligned}
& \frac{\mathrm{d} M_{\mathrm{w}}}{\mathrm{d}_{t}}=E_{\mathrm{r}}+E_{\mathrm{a}}+M_{\mathrm{s}} k_{5}-M_{\mathrm{w}}\left(k_{1}+k_{2}+k_{3}+k_{4}\right) \\
& \frac{\mathrm{d} M_{\mathrm{s}}}{\mathrm{d}_{t}}=M_{\mathrm{w}} k_{4}-M_{\mathrm{s}}\left(k_{5}+k_{6}+k_{7}\right)
\end{aligned}
$$

where $t$ is the time $\left(\mathrm{d}^{-1}\right)$. Detailed equations for the calculation of $k_{1}-k_{7}\left(\mathrm{~d}^{-1}\right)$ are described in Text S1.2. The result values are listed in Tables S1 and S2.

\section{RESULTS AND DISCUSSION}

3.1. BFR Concentrations in Surface Freshwater and River Sediment. Table 1 summarizes the concentrations of target BFRs in freshwater and river sediment. Only EHTBB and DPTE were not detected in freshwater and river sediment samples, suggesting that there was no significant source for these compounds in the study area. The mean $\sum$ BFRs concentrations in the dissolved phase and particulate phase in freshwater accounted for 0.5 and $99.5 \%$ of $\sum$ BFRs concentration in freshwater, respectively. This finding corresponds to the relatively high hydrophobicity $\left(\log K_{\mathrm{ow}}>5.87\right.$ ) and low solubility $\left(0.0001-0.78 \mathrm{mg} \mathrm{L}^{-1}\right)$ of BFRs. ${ }^{29-32}$ Eleven freshwater column samples were damaged during the experiment. As the particulate $\sum$ BFRs concentration was the dominant component, it could almost represent the $\sum$ BFRs concentration in freshwater; hence, we only discuss the 
particulate phase hereinafter. The mean $\sum_{7} \mathrm{PBDEs}$ and $\mathrm{BDE}$ 209 concentrations were $0.60 \pm 3.05$ and $18.3 \pm 85.6 \mathrm{ng} \mathrm{L}^{-1}$, respectively. The minor contributions of BDE $99(<6.0 \%)$ and BDE $183(<1.9 \%)$ in this study area suggested minor contributions of penta-BDE and octa-BDE, which were completely phased out in 2004 in China. ${ }^{33}$ Therefore, BDE 209 was the main component of the $\sum$ PBDEs concentration (the sum of $\sum_{7} \mathrm{PBDEs}$ and BDE 209), which agrees with the fact that deca-BDE is the most widely used commercial product among the three PBDE products in China ${ }^{32}$ and was not restricted in China until very recently. ${ }^{5}$ In terms of NBFRs, $\sum_{4}$ NBFR and DBDPE concentrations ranged from 0.0001 to $3.48 \mathrm{ng} \mathrm{L}^{-1}$ and from 0.048 to $14.4 \mathrm{ng} \mathrm{L}^{-1}$, respectively. The DBDPE concentration was the second highest after that of BDE 209. In fact, DBDPE, as a replacement for BDE 209, was the second-highest currently used additive BFR in China. ${ }^{31,33}$ The highest BDE 209 concentration was observed in the Mi River (501 ng L ${ }^{-1}$ ) (Table S3), which exceeded that reported for other water bodies worldwide (Table S4)..$^{24,34-36}$ Moreover, the BDE 209 concentrations in 10 of the 33 rivers and in 22 of the 33 rivers in the present study exceeded those reported for the Dongjiang River in South China (3.67 ng $\left.\mathrm{L}^{-1}\right)^{34}$ and the San Francisco Estuary in the United States $\left(0.51 \mathrm{ng} \mathrm{L}^{-1}\right),{ }^{26,35}$ respectively. The data for DBDPE in fresh water bodies worldwide is limited; the DBDPE concentrations in 24 of the 33 rivers sampled in this study were higher or comparable to that reported for the Dongjiang River (Table S4). ${ }^{35}$ Hence, our results reveal high levels of BDE 209 and DBDPE contaminations in the rivers, which indicated the huge and recent use/emission of these chemicals in North China. ${ }^{37,52}$

In river sediment, the $\sum$ NBFRs concentration contributed between 70 and $99.5 \%$ to the $\sum$ BFRs concentration and ranged from $0.018 \mathrm{ng} \mathrm{g}^{-1} \mathrm{dw}$ to $206 \mathrm{ng} \mathrm{g}^{-1} \mathrm{dw}$ (mean: $14.3 \mathrm{ng}$ $\mathrm{g}^{-1} \mathrm{dw} \pm 36.1 \mathrm{ng} \mathrm{g}^{-1} \mathrm{dw}$, Table S5). BDE 209 and DBDPE were also the two major compounds. Extremely high sedimentary concentrations of DBDPE and BDE 209 were both observed in the Mi River, which were all $1-3$ orders of magnitude greater than those in the remaining rivers (Table S3). Besides, the DBDPE and BDE 209 concentrations in sediment from the Mi River were both relatively high in comparison to those reported in previous studies. ${ }^{39}$ However, the sedimentary DBDPE concentrations in 28 of the 35 rivers $\left(<18 \mathrm{ng} \mathrm{g}^{-1} \mathrm{dw}\right)$ were lower than those of a previous study (Table S6). In addition, the BDE 209 concentrations in 23 of 35 rivers in this study $\left(<2.79 \mathrm{ng} \mathrm{g}^{-1} \mathrm{dw}\right)$ were considerably lower than that found in previous studies (Table S6). This suggests that sporadic historical emission sources of DBDPE and BDE 209 may exist around many rivers in North China.

3.2. BFR Concentrations in Surface Seawater, Bottom Seawater, and Marine Sediment. Like the river samples, EHTBB and DPTE were not detected in any of the marine samples. We only discuss particulate BFR concentrations due to the low proportions of dissolved BFR concentrations in the surface $(<4.0 \%)$ seawater and bottom seawater $(<4.0 \%)$ samples. The $\sum$ PBDE concentrations in surface seawater and bottom seawater ranged from n.d. to $11.3 \mathrm{ng} \mathrm{L}{ }^{-1}$ (mean: $0.42 \pm 0.61 \mathrm{ng} \mathrm{L}^{-1}$ ) and from n.d. to $0.94 \mathrm{ng} \mathrm{L}^{-1}$ (mean: 0.23 $\pm 0.19 \mathrm{ng} \mathrm{L}^{-1}$ ), respectively. BDE 209 accounted for 89-100 and $80-100 \%$ of the $\sum$ PBDE concentrations in surface seawater and bottom seawater, respectively, which was consistent with the results for the river samples. The DBDPE concentrations in surface seawater and bottom seawater ranged from n.d. to $1.45 \mathrm{ng} \mathrm{L^{-1 }}$ (mean: $0.15 \pm$ $0.23 \mathrm{ng} \mathrm{L}^{-1}$ ) and from n.d. to $0.33 \mathrm{ng} \mathrm{L}^{-1}$ (mean: $0.085 \pm$ $0.074 \mathrm{ng} \mathrm{L}^{-1}$ ), respectively (Tables 1 and S7). DBDPE was the dominant compound, with proportions of 73-100 and 78$100 \%$ of the $\sum$ NBFR concentrations in surface seawater and bottom seawater, respectively. For the same site, the BDE 209 concentration of surface seawater samples (mean: $0.63 \mathrm{ng} \mathrm{L}^{-1}$ ) was $\sim 3$ times higher than that of bottom seawater samples (mean: $0.22 \mathrm{ng} \mathrm{L}^{-1}$ ). In comparison to other studies, the level of BDE 209 in seawater was at a high level (Table S4). ${ }^{27,40,41}$ China is the biggest producer and supplier of deca-BDE worldwide. ${ }^{33,42}$ In addition, the Shandong Province, which is neighboring the BS, has been the largest manufacturing base of deca-BDE since 1995 in China. ${ }^{34}$ Therefore, a large amount of surface runoff with a relatively high BDE 209 concentration has been discharged into the BS. In fact, some rivers discharging into the BS had relatively high concentrations of BDE 209 in this study (Table S3). Wang et al. ${ }^{15}$ illustrated that the relatively low water exchange in the $\mathrm{BS}$ results in inefficient diffusion of pollutants in this region. Hence, historical usage, recent emission, and hydrodynamics had contributed to the relatively high BDE 209 in the BS. DBDPE concentration of surface seawater samples (mean: $0.089 \mathrm{ng} \mathrm{L}^{-1}$ ) was also slightly higher than that of bottom seawater samples (mean: $0.063 \mathrm{ng} \mathrm{L}^{-1}$ ). DBDPE concentration was $\sim 10$ times higher than that measured in Lake Ontario in North America (Table S4). ${ }^{27}$

The BDE 209 and DBDPE concentrations of marine sediments ranged from n.d. to $17.7 \mathrm{ng} \mathrm{g}^{-1} \mathrm{dw}$ and from n.d. to $11.2 \mathrm{ng} \mathrm{g}^{-1} \mathrm{dw}$, respectively (Tables 1 and S8). BDE 209 and DBDPE in marine sediment accounted for $50-100 \%$ of the $\sum$ PBDE concentration and $82-100 \%$ of $\sum$ NBFR concentration, respectively. The BDE 209 concentration of marine sediment samples in this study was approximately 2 to 4 times lower than that of samples collected in 2006 (mean: $7.00 \mathrm{ng} \mathrm{g}^{-1} \mathrm{dw}$ ) and 2009 (mean: $5.10 \mathrm{ng} \mathrm{g}^{-1} \mathrm{dw}$ ) in the BS. ${ }^{25,43}$ Chen et al. ${ }^{38}$ found that a substantial decline in the release of PBDEs into rivers had occurred over recent years following the declaration of China's Restriction of Certain Hazardous Substances (RoHS) in 2006. In addition, the annual production and emission of deca-BDE in China have decreased since 2005. ${ }^{33}$ Meanwhile, BDE 209 is known to easily degrade to lower PBDE congeners. ${ }^{44}$ Therefore, the decrease in BDE 209 levels might be ascribed both to a reduction in the production and use of PBDEs in manufacturing industries and to its degradation (Section 3.4).

3.3. Spatial Distribution and Tentative Exploration of BFR Sources. Figure $S 1$ shows the distribution of $\sum_{2} B F R$ (the sum of DBDPE and BDE 209) in the 33 rivers discharging into the $\mathrm{BS}$ and NYS. The mean $\sum_{2} \mathrm{BFR}$ concentrations in the rivers exhibited the following trend: production area $>$ urban area $>$ urban-rural area $>$ rural area. The top five rivers with the highest $\sum_{2} \mathrm{BFR}$ concentrations (water and sediment) were the Majia, Tuhai, Zimai, Mi, and Yu rivers, which are all located in Shandong Province. Shandong Province is the largest BFR manufacturing base in North China, ${ }^{33}$ where DBDPE and BDE 209 have been in mass production up until recently. ${ }^{45,46}$ Furthermore, the top two highest $\sum_{2} \mathrm{BFR}$ concentrations in water and sediment were observed in the Mi River, where there is a large BFR manufacturing factory ${ }^{45}$ (Figure S2). Therefore, these manufacturing bases are likely the most important sources of BFRs to rivers located in the production area. The sediment of the Tang, Chaobai, and Hai 

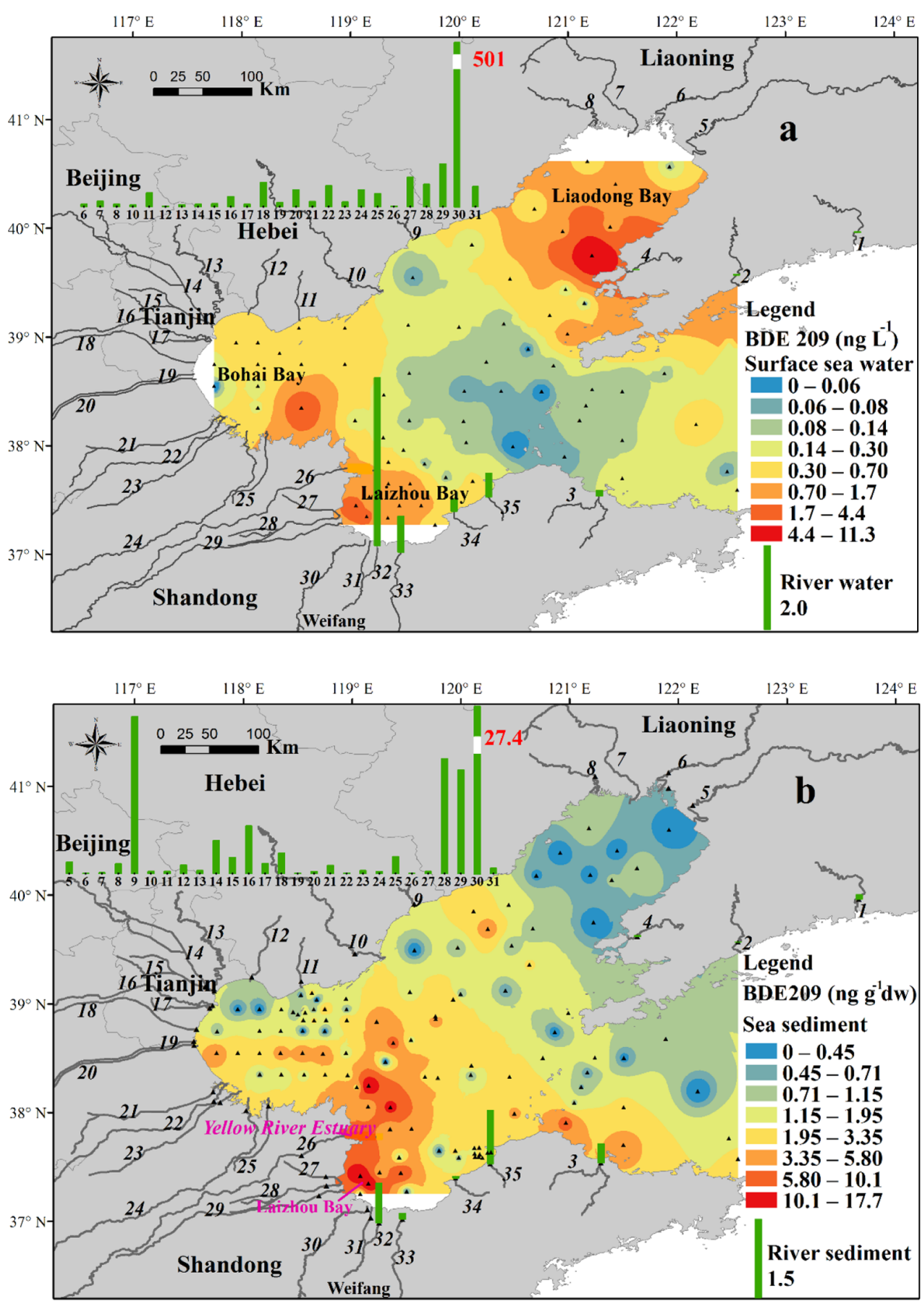

Figure 2. Distribution pattern of BDE 209 in surface water (freshwater and seawater) (a) and sediment (river sediment and marine sediment) (b) in the BS.

rivers all had relatively high $\sum_{2} B F R$ concentrations. The Chaobai River flows through Beijing, Heibei, and Tianjin, whereas the Hai and Tang rivers flow through Tianjin and Qinghuangdao cities, respectively. These are all industrial cities with more than one million inhabitants, who inevitably use electronics, foams (building), furnishing materials, plastics, and textiles containing BFRs. ${ }^{6,47}$ In addition, Lin et al. ${ }^{48}$ pointed out that an e-waste recycling site is in southern Tianjin. Hence, the high levels of DBDPE and BDE 209 in these three rivers are, to some extent, the result of emissions related to the use and disposal of products containing BFRs.

In surface seawater, DBDPE was positively correlated with BDE 209 (Table S9), and these two BFRs also exhibited the same distribution characteristics (Figures 2 and S4), which indicated a similar source and fate. The BDE 209 concentration of seawater decreased with increasing distance from the coastal area to the offshore area (Figure 2a). A strong negative correlation was also determined between BDE 209 and salinity (Table S10), suggesting the contribution of 
terrigenous inputs and dilution by open seawater. Another important observation was that a relatively high BDE 209 concentration was found in LZB, which corresponded to relatively high $\sum_{2} B F R$ concentrations in most of the rivers discharging into LZB. In our previous study, we suggested that the Xiaoqing River is an important source of BFRs to LZB because it is impacted by a large BFR manufacturing base. ${ }^{24}$ Atmospheric transport and deposition may also input POPs to the sea. ${ }^{49,50}$ Zhao et al. ${ }^{1}$ reported that the highest atmospheric concentrations of BDE 209 and DBDPE occurred around LZB, which was affected by the BFR manufacturing base. Our previous study also reported that relatively high BFR concentrations were observed in both seawater and low atmosphere of the LZB. ${ }^{20}$ Thus, riverine and atmosphere inputs might affect the distribution of BFRs in the BS. Moreover, SPM, POC, and PBC could provide adsorption surfaces for hydrophobic organic compounds, ${ }^{20,50,51}$ especially for BDE 209 and DBDPE. The results showed that SPM, POC, and $\mathrm{PBC}$ concentrations were significantly correlated with BDE 209 (or DBDPE) in seawater (Table S11), suggesting a strong impact of environmental parameters on BFR distributions. These two BFR distribution characteristics in bottom seawater were also similar to those in surface seawater (Figure S4). In addition, similar PBDE compositions (except for BDE 209, Figure S5) were obtained in the bottom and surface seawater, with the predominant congener being BDE 183. Another study found that SPM was mostly concentrated during the summer season in the BS. ${ }^{53}$ Thus, the BDE 209 distribution in the bottom water was mostly affected by sedimentation.

In marine sediments, high BDE 209 (Figure 2b) and DBDPE concentrations (Figure S4b) were both found in LZB and the northern part of the Yellow River Delta (NYRD). First, river estuaries discharging into LZB had relatively high BDE 209 and DBDPE concentrations. Second, sediment derived from the Yellow River is a dominant source of sediment to the BS. $^{53}$ These two regions had relatively high SPM concentrations and sedimentation rates (Figure S6). The water column exhibited high stratification; thus, vertical mixing was remarkably weakened. ${ }^{20}$ Such hydrodynamic processes contributed to the rapid deposition of river-derived sediments in the river mouth. Wang et al. ${ }^{53}$ suggested that the Yellow River Delta is a major sink for terrestrial sediment during the summer. Hence, fine suspended particles with high BFR concentrations became trapped in the current and were transported from the shore to these two regions before finally settling out in LZB and the NYRD. In addition, both the TOC content and median diameters (MD) of sediments (Figure S6) were significantly correlated with BDE 209 (or DBDPE). These findings imply that the physicochemical properties of sediment could also affect the BFR distribution.

3.4. Characteristics of BDE209/DBDPE Ratios in Various Environmental Media: Indicators of Their Usage Pattern in North China and Differential Transport Patterns. As mentioned, BDE 209 and DBDPE were predominant in all samples. The physicochemical properties of DBDPE are similar to those of BDE 209 due to its structural resemblance to BDE 209. ${ }^{31,54}$ As the best replacement of decaBDE, DBDPE has similar applications. The results revealed significant correlations between BDE 209 and DBDPE in different environmental media (Table S9), indicating their common sources and fates. A total of 33 rivers flow through major provinces in North China, including Liaoning, Beijing,
Tianjin, Hebei, and Shandong provinces, and collectively account for more than $90 \%$ of the total riverine input into the BS. $^{21}$ The pollutant levels in freshwater reflect the current contaminant status; hence, the characteristics of BDE 209/ DBDPE ratios in various environmental media could provide information on their usage patterns in North China and differential transport patterns.

The BDE 209/DBDPE ratios in 12 out of 33 rivers (water) were $\leq 1.0$. In contrast, He et al. ${ }^{35}$ reported BDE 209/DBDPE ratios of 1.32-2.94 for the Dongjiang River in South China. In particular, the proportion of rivers with BDE 209/DBDPE ratios below or comparable to 1.0 in the total of 33 rivers was decreased significantly from rural areas ( 3 out of 4 ) to urbanrural (4 out of 10), urban (4 out of 13), and BFR production area (1 out of 6) (Figure S3). Besides, the same decreasing trend was observed in the mean BDE 209/DBDPE ratio from the production area $(13.1 \pm 19.2)$ to rural areas $(0.89 \pm 0.73)$. DBDPE became a commercially important formulation in the early 1990s. Most of the rivers in the production area are located in the Shandong Province. In fact, the annual production of BDE 209 ( 8000 tons) by Haiwang Chemical Co. Ltd. in the Shandong Province was higher than that of DBDPE (6000 tons). ${ }^{45}$ In this paper, BDE 209 is the major component in most rivers affected by BFR production as well as most urban rivers. However, low BDE 209/DBDPE ratios in most rural rivers with low BFR concentrations and in certain urban rivers (e.g., the Majia and Tuhai rivers) indicate that a shift in the contamination patterns of these two BFRs has occurred in North China. Similarly, this shift also reflects a change in their usage patterns in North China.

Figure 3 shows BDE 209/DBDPE ratios of five environmental media in the present study. The most noteworthy

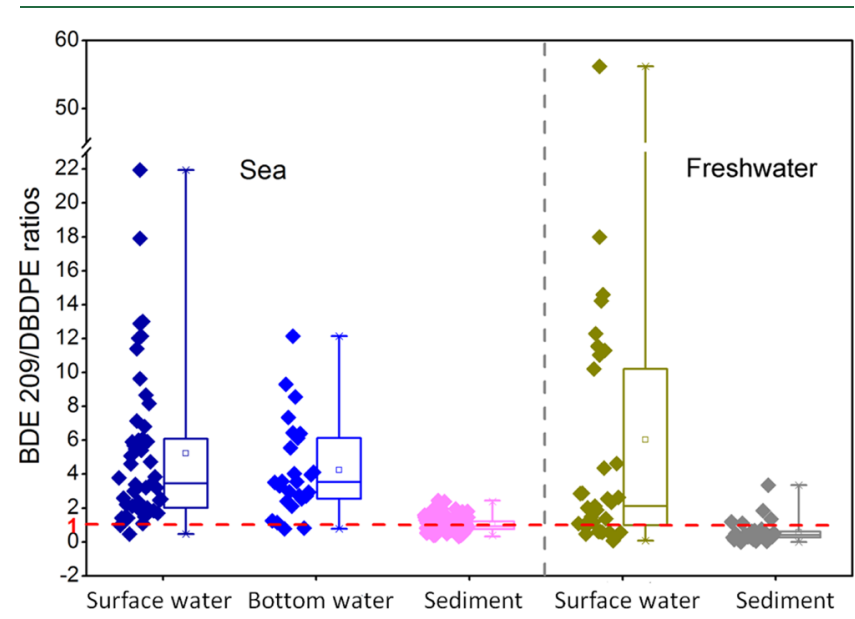

Figure 3. BDE 209/DBDPE ratios in surface seawater, bottom seawater, marine sediment, freshwater, and river sediment.

feature is that the ratios in water (river and marine) were all higher than those in sediment. Moreover, the BDE 209/ DBDPE ratio decreased between the surface seawater (5.13 \pm $4.55)$ and bottom seawater $(4.13 \pm 2.73)$ and then decreased further in sediment $(0.93 \pm 1.14)$. Compared to water, sediment could reflect POPs contamination over many years. The different ratios in water and sediment reflect their differential transport patterns. Compared to BDE 209 (log $\left.K_{\text {ow }}: 9.97\right)$, DBDPE has a relatively higher $\log K_{\text {ow }}(11.1)$ and low water solubility. ${ }^{55,56}$ In water-dissolved phase, BDE 209 concentrations were higher than DBDPE concentrations 

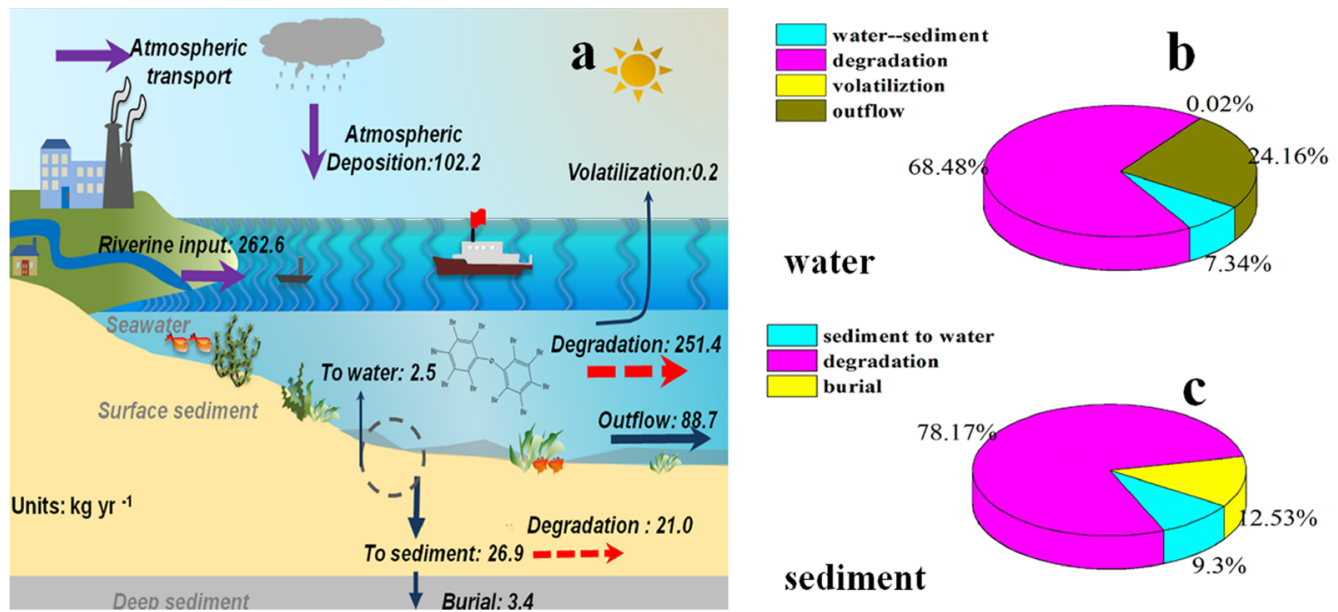

\section{$\square$ sediment to water}

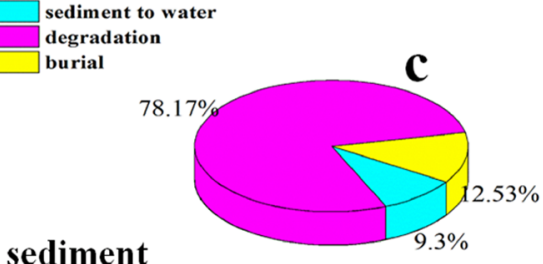

Figure 4. Budget of BDE 209 using a multi-box mass balance model of the BS (a); proportions of BDE 209 sinks in BS water (b); proportions of BDE 209 sinks in BS sediment (c).

(Table 1). BDE 209/DBDPE ratios in dolphin and porpoise were both $>1$ in the South China Sea. ${ }^{57}$ Compared to DBDPE, there was a significant correlation between chlorophyll $a$ and BDE 209 in surface seawater (Table S11). Zhu et al. ${ }^{57}$ also considered that DBDPE had a relatively lower bioavailability and bioaccumulation potential than BDE 209 due to the larger molecular weight of DBDPE, though there was no assured information on the bioaccumulation/biomagnification of DBDPE in a marine environment. Besides, photodegradation of BDE 209 was faster than that of DBDPE in natural sunlight. ${ }^{54}$ Tokarz et al. ${ }^{44}$ demonstrated that BDE 209 could dehalogenate to nona-, octa-, hepta-, and hexa-PBDEs by microbial degradation in sediments. Bezares-Cruz et al. ${ }^{58}$ reported that BDE 209 dehalogenated from deca- to tri-PBDEs by photodegradation in a solvent. ${ }^{58}$ Considering the global restriction of penta-BDE and octa-BDE after 2009, only decaBDE was used in China. ${ }^{59}$ Thus, low-brominated PBDEs were mainly derived from the degradation of higher brominated PBDEs. In addition, strong correlations between BDE 209 and seven low brominated PBDEs were found in five environmental media in this study (Table S12). Meanwhile, there was a relatively strong correlation between the $\mathrm{MD}$ of sediments and BDE 209 compared to DBDPE (Table S13), indicating that DBDPE had a relatively higher affinity to fine sediment particles. Therefore, for water, the higher degradation and bioavailability of BDE 209 may contribute to the decreased BDE 209/DBDPE ratio from surface water to bottom water. For sediment, the lowest BDE 209/DBDPE ratio was dominated by differential degradation of these two BFRs and their different affinities to fine sediment particles.

3.5. River Flux and Budget of BFRs Using a Multi-Box Mass Balance Model. 3.5.1. River Flux of BFRs into the BS. The calculation method for river discharge and the results are given in Text S1.1 and Table S3, respectively. The total inputs of BDE 209 and DBDPE through the inflow of 30 rivers to the BS were 263 and $35.4 \mathrm{~kg} \mathrm{yr}^{-1}$ (Figure 4a), respectively. When compared with the atmospheric deposition of BDE $209(\sim 102$ $\left.\mathrm{kg} \mathrm{yr}^{-1}\right)$ and DBDPE $\left(\sim 145 \mathrm{~kg} \mathrm{yr}^{-1}\right)$ during 2016-2017 from our previous study (Text S1.3, Table S14), ${ }^{20}$ riverine inputs contributed $\sim 72$ and $\sim 20 \%$ of the total BDE 209 and DBDPE inputs, respectively. In addition, riverine inputs to LZB (10 rivers) (Figure S7) accounted for $\sim 90$ and $\sim 51 \%$ of the total BDE 209 and DBDPE riverine input, respectively. The Mi
River alone contributed $\sim 80 \%\left(212 \mathrm{~kg} \mathrm{yr}^{-1}\right)$ of the total riverine $\mathrm{BDE} 209$ input. Hence, there is concern regarding the rivers around the BFR manufacturing base.

3.5.2. Concentrations and Budget of BDE 209 under Steady-State Conditions Using a Multi-Box Mass Balance Model. We used a multi-box mass balance model to predict the concentrations and fate of BDE 209 by assuming a constant input of BDE 209 to the BS. The results showed that the BDE 209 concentration in water decreased rapidly in the first year and then decreased slightly until reaching nearly stable state values $\left(\mathrm{d} M / \mathrm{d} t \leq-10^{-5}\right)$ after 18 years of simulation (Figure S8). The simulated BDE 209 concentration during 2016-2017 ranged from 0.12 to $0.14 \mathrm{ng} \mathrm{L}^{-1}$, which was $\sim 2$ times higher than the observation mean BDE 209 concentration (0.057 \pm $\left.0.060 \mathrm{ng} \mathrm{L}^{-1}\right) .^{20} \mathrm{In}$ fact, the riverine input of BDE 209 into the BS varied and had a great influence on the BDE 209 concentration in seawater. The measured BDE 209 concentrations in sediments collected in 2006, 2009, and 2013 were $7.00 \mathrm{ng} \mathrm{g}^{-1} \mathrm{dw},{ }^{43} 5.10 \mathrm{ng} \mathrm{g}^{-1} \mathrm{dw}^{25}$ and $2.47 \mathrm{ng} \mathrm{g}^{-1} \mathrm{dw}$, respectively, thus presenting a decreasing temporal trend of BDE 209 concentration in the BS. The simulated BDE 209 concentration in sediment decreased over time until reaching the steady-state scenario after 25 years. The only difference was that the simulated BDE 209 concentration decreased more slowly over time in comparison to the measured concentration.

The multi-box mass balance model was run for seawater and sediment to calculate the contributions of transport and transformation processes under steady-state conditions. The model results showed that degradation was the primary sink of BDE $209(\sim 68 \%)$ in seawater of the BS, followed by outflow to the NYS ( 24\%), water to sediment transformation (the sum of sedimentation and diffusion, $\sim 7.3 \%$ ), and volatilization $(<0.1 \%)$ (Figure $4 \mathrm{~b})$. This finding differed from previous BC and $\mathrm{PAH}$ budgets, which reveal that deposition to sediment was the main sink in the BS. ${ }^{15,21}$ The difference between these budgets is because degradation was included in our model and the target compound was different. Schenker et al. ${ }^{60}$ also reported that the degradation of heavier PBDEs (from hexa$\mathrm{BDE}$ to deca-BDE) in the atmosphere of the emission zone contributed $45 \%$ of the loss processes, which was higher than deposition (30\%), highlighting the importance of degradation. Besides, degradation of BDE 209 occurred widely in seawater and marine sediment in the BS (Section 3.4). When removing 
the degradation process in the model (Figure S9), the BDE 209 concentration during 2016-2017 ranged from 0.43 to $0.55 \mathrm{ng} \mathrm{L}^{-1}$, which was 10 times higher than the observed BDE 209 concentration; hence, degradation was the primary output process of BDE 209 in the BS. Highly hydrophobic BDE 209 tends to adsorb onto SPM, which is then transported and deposited. Qiao et al. ${ }^{61}$ found that sediment trapped in the BS (>30\% of the total sediment inflowing into the BS) was higher than that escaping to the NYS (20\%). Thus, outflow to the NYS could also be another significant output process. In terms of surface sediment, the results showed that $\sim 78, \sim 13$, and $\sim 9.0 \%$ of the sink were ascribed to degradation, burial to deep sediment, and sediment to water transformation (the sum of resuspension and diffusion) (Figure 4c), respectively. Degradation was also the primary output process for BDE 209 in sediment. Significantly, the uncertainty of outcome (BDE 209 concentration at steady state) of the model was thus based on the errors in $E_{a}, k_{1}, k_{3}$, and $k_{6}$ (Text S1.6). Therefore, the uncertainty was ranged from -74 to $113 \%$, which was determined based on the error in these four individual parameters.

Although BDE 209 is a persistent environmental pollutant, results suggested that degradation plays a significant role in the removal process of BDE 209 in water and sediment. It is undeniable that the simulation results had some limitations, such as the lack of a biological removal process for BDE 209 and continuous observation of BDE 209 values of freshwater and seawater. In addition, the half-life values of BDE 209 in water and sediment played a predominant role in the sensitivity of the model (Text S1.5) and were both obtained by EPIWIN ${ }^{62}$ due to a lack of field-measured data in the BS. However, the multi-box model provided a nice way to understand the BFRs' environmental behavior and fate. Future studies should focus on obtaining more field-measured data to accurately simulate the fate of BDE 209.

\section{ASSOCIATED CONTENT}

\section{SI Supporting Information}

The Supporting Information is available free of charge at https://pubs.acs.org/doi/10.1021/acs.est.0c08528.

Detailed information on study area, all parameters of BDE 209 and DBDPE used; concentration and riverine input of $\sum 7$ PBDEs, $\sum 4$ NBFRs, BDE 209, and DBDPE in $\mathrm{kg} \mathrm{yr}-1$ in the surveyed 33 rivers; comparison BFR concentration in water samples and surface sediment; concentration of BDE 209, DBDPE, and BFRs in surface and bottom seawater and marine sediment; correlations between BDE 209 and DBDPE in freshwater, river sediment, surface seawater, bottom seawater and sea sediment; correlation between BDE 209 and salinity in present study; correlation between two major BFRs and some environmental parameters; correlations between median diameters and total organic carbon of sea sediments and two major BFRs in sea sediment; values of BDE 209 in atmosphere in the BS; distribution pattern of $\sum 2 B F R$ in surface river sediment and freshwater sediment; major BFRs manufactories distribution in the Shandong Province; distribution of BDE 209/DBDPE ratios in surface freshwater in 33 river estuaries; distribution pattern of DBDPE in surface water and sediment; contributions of PBDEs congeners; distributions of sediment $\mathrm{MD}$, sediment TOC, sed- imentation rate, and SPM; riverine inputs of BDE 209 and DBDPE; simulation variation trends of BDE 209 concentration in seawater and sea sediment (PDF)

\section{AUTHOR INFORMATION}

\section{Corresponding Author}

Jianhui Tang - CAS Key Laboratory of Coastal

Environmental Processes and Ecological Remediation, Yantai Institute of Coastal Zone Research (YIC), Chinese Academy of Sciences (CAS); Shandong Key Laboratory of Coastal Environmental Processes, YICCAS, Yantai 264003, China; Center for Ocean Mega-Science, Chinese Academy of Sciences, Qingdao 266071, China; 이이.org/0000-0002-9006263X; Email: jhtang@yic.ac.cn

\section{Authors}

Xiaomei Zhen - State Key Laboratory of Organic Geochemistry, Guangzhou Institute of Geochemistry, Chinese Academy of Sciences (CAS), Guangzhou 510631, China; CAS Key Laboratory of Coastal Environmental Processes and Ecological Remediation, Yantai Institute of Coastal Zone Research (YIC), Chinese Academy of Sciences (CAS); Shandong Key Laboratory of Coastal Environmental Processes, YICCAS, Yantai 264003, China; University of Chinese Academy of Sciences (UCAS), Beijing 100049, China

Yanfang Li - CAS Key Laboratory of Coastal Environmental Processes and Ecological Remediation, Yantai Institute of Coastal Zone Research (YIC), Chinese Academy of Sciences (CAS); Shandong Key Laboratory of Coastal Environmental Processes, YICCAS, Yantai 264003, China; Center for Ocean Mega-Science, Chinese Academy of Sciences, Qingdao 266071, China

Xinming Wang - State Key Laboratory of Organic Geochemistry, Guangzhou Institute of Geochemistry, Chinese Academy of Sciences (CAS), Guangzhou 510631, China; (1) orcid.org/0000-0002-1982-0928

Lin Liu - State Key Laboratory of Organic Geochemistry, Guangzhou Institute of Geochemistry, Chinese Academy of Sciences (CAS), Guangzhou 510631, China; CAS Key Laboratory of Coastal Environmental Processes and Ecological Remediation, Yantai Institute of Coastal Zone Research (YIC), Chinese Academy of Sciences (CAS); Shandong Key Laboratory of Coastal Environmental Processes, YICCAS, Yantai 264003, China; University of Chinese Academy of Sciences (UCAS), Beijing 100049, China

Mingyu Zhong - Yantai University, Yantai, Shandong 264005, China

Chongguo Tian - CAS Key Laboratory of Coastal Environmental Processes and Ecological Remediation, Yantai Institute of Coastal Zone Research (YIC), Chinese Academy of Sciences (CAS); Shandong Key Laboratory of Coastal Environmental Processes, YICCAS, Yantai 264003, China; Center for Ocean Mega-Science, Chinese Academy of Sciences, Qingdao 266071, China; (1) orcid.org/0000-0001-60589353

Complete contact information is available at: https://pubs.acs.org/10.1021/acs.est.0c08528

\section{Notes}

The authors declare no competing financial interest. 


\section{ACKNOWLEDGMENTS}

This study was supported by the National Natural Science Foundation of China (NSFC) - Shandong Province Joint Fund (no. U1806207) and NSFC (41773138), key project of Chinese Academy of Sciences (XDA11020402), key deployment project of Centre for Ocean Mega- Science, Chinese Academy of Sciences (COMS2019J08) and by the seed project of Yantai Institute of Coastal Zone Research, Chinese Academy of Sciences (no. YIC Y855011024).

\section{REFERENCES}

(1) Zhao, Y.; Ma, J.; Qiu, X.; Lin, Y.; Yang, Q.; Zhu, T. Gridded field observations of polybrominated diphenyl ethers and decabromodiphenyl ethane in the atmosphere of north China. Environ. Sci. Technol. 2013, 47, 8123-8129.

(2) Liu, H.-H.; Hu, Y.-J.; Luo, P.; Bao, L.-J.; Qiu, J.-W.; Leung, K. M. Y.; Zeng, E. Y. Occurrence of halogenated flame retardants in sediment off an urbanized coastal zone: association with urbanization and industrialization. Environ. Sci. Technol. 2014, 48, 8465-8473.

(3) Yadav, I. C.; Devi, N. L.; Li, J.; Zhang, G. Environmental concentration and atmospheric deposition of halogenated flame retardants in soil from Nepal: Source apportionment and soil-air partitioning. Environ. Pollut. 2018, 233, 642-654.

(4) Zhao, Z.; Xie, Z.; Tang, J.; Sturm, R.; Chen, Y.; Zhang, G.; Ebinghaus, R. Seasonal variations and spatial distributions of perfluoroalkyl substances in the rivers Elbe and lower Weser and the North Sea. Chemosphere 2015, 129, 118-125.

(5) Stockholm Convention. The POPs. http://chm.pops.int/ TheConvention/ThePOPs/tabid/673/Default.aspx (accessed on October 5,2020$)$.

(6) Möller, A.; Xie, Z.; Cai, M.; Zhong, G.; Huang, P.; Cai, M.; Sturm, R.; He, J.; Ebinghaus, R. Polybrominated diphenyl ethers vs alternate brominated flame retardants and Dechloranes from East Asia to the Arctic. Environ. Sci. Technol. 2011, 45, 6793-6799.

(7) Li, B.; Wang, K.; Ma, L.-X.; Sun, S.-J.; Jia, L.-R.; Yuan, A.-N.; Shen, J.-M.; Qi, H.; Zhang, A.-P. Deca-BDE and alternative halogenated flame retardants in a wastewater treatment plant in Harbin (2009-2016): Occurrence, temporal trends, seasonal variation, and fate. Sci. Total Environ. 2018, 625, 1156-1163.

(8) Zheng, Q.; Nizzetto, L.; Li, J.; Mulder, M. D.; Sáňka, O.; Lammel, G.; Bing, H.; Liu, X.; Jiang, Y.; Luo, C.; Zhang, G. Spatial distribution of old and emerging flame retardants in Chinese forest soils: sources, trends and processes. Environ. Sci. Technol. 2015, 49, 2904-2911.

(9) Munschy, C.; Olivier, N.; Veyrand, B.; Marchand, P. Occurrence of legacy and emerging halogenated organic contaminants in marine shellfish along French coasts. Chemosphere 2015, 118, 329-335.

(10) Möller, A.; Xie, Z.; Caba, A.; Sturm, R.; Ebinghaus, R. Occurrence and air-seawater exchange of brominated flame retardants and Dechlorane Plus in the North Sea. Atmos. Environ. 2012, 46, 346-353.

(11) Zhen, X.; Tang, J.; Xie, Z.; Wang, R.; Huang, G.; Zheng, Q.; Zhang, K.; Sun, Y.; Tian, C.; Pan, X.; Li, J.; Zhang, G. Polybrominated diphenyl ethers (PBDEs) and alternative brominated flame retardants (aBFRs) in sediments from four bays of the Yellow Sea, North China. Environ. Pollut. 2016, 213, 386-394.

(12) Antoine, D.; André, J.-M.; Morel, A. Oceanic primary production: 2. Estimation at global scale from satellite (Coastal Zone Color Scanner) chlorophyll. Global Biogeochem. Cycles 1996, 10, 57-69.

(13) Peng, D.; Yang, Q.; Yang, H.-J.; Liu, H.; Zhu, Y.; Mu, Y. Analysis on the relationship between fisheries economic growth and marine environmental pollution in China's coastal regions. Sci. Total Environ. 2020, 713, 136641.

(14) Zhao, Z.; Zhong, G.; Möller, A.; Xie, Z.; Sturm, R.; Ebinghaus, R.; Tang, J.; Zhang, G. Levels and distribution of Dechlorane Plus in coastal sediments of the Yellow Sea, North China. Chemosphere 2011, 83, 984-990.

(15) Wang, C. L.; Zou, X. Q.; Zhao, Y. F.; Li, Y. L.; Song, Q. C.; Wang, T.; Yu, W. W. Distribution pattern and mass budget of sedimentary polycyclic aromatic hydrocarbons in shelf areas of the Eastern China Marginal Seas. J. Geophys. Res.: Oceans 2017, 122, 4990-5004.

(16) Pan, X.; Tang, J.; Chen, Y.; Li, J.; Zhang, G. Polychlorinated naphthalenes (PCNs) in riverine and marine sediments of the Laizhou Bay area, North China. Environ. Pollut. 2011, 159, 35153521.

(17) Wang, R.; Tang, J.; Xie, Z.; Mi, W.; Chen, Y.; Wolschke, H.; Tian, C.; Pan, X.; Luo, Y.; Ebinghaus, R. Occurrence and spatial distribution of organophosphate ester flame retardants and plasticizers in 40 rivers draining into the Bohai Sea, north China. Environ. Pollut. 2015, 198, 172-178.

(18) Liu, L.; Tang, J.; Zhong, G.; Zhen, X.; Pan, X.; Tian, C. Spatial distribution and seasonal variation of four current-use pesticides (CUPs) in air and surface water of the Bohai Sea, China. Sci. Total Environ. 2018, 621, 516-523.

(19) Wang, G.; Peng, J.; Xu, X.; Zhang, D.; Li, X. Polybrominated diphenyl ethers in sediments from the Southern Yellow Sea: Concentration, composition profile, source identification and mass inventory. Chemosphere 2016, 144, 2097-2105.

(20) Liu, L.; Zhen, X.; Wang, X.; Li, Y.; Sun, X.; Tang, J. Legacy and novel halogenated flame retardants in seawater and atmosphere of the Bohai Sea: Spatial trends, seasonal variations, and influencing factors. Water Res. 2020, 184, 116117.

(21) Fang, Y.; Chen, Y.; Tian, C.; Lin, T.; Hu, L.; Huang, G.; Tang, J.; Li, J.; Zhang, G. Flux and budget of $\mathrm{BC}$ in the continental shelf seas adjacent to Chinese high BC emission source regions. Global Biogeochem. Cycles 2015, 29, 957-972.

(22) Mackay, D.; Sang, S.; Vlahos, P.; Diamond, M.; Gobas, F.; Dolan, D. A Rate Constant Model ofChemical Dynamics in a Lake Ecosystem: PCBs in Lake Ontario. J. Great Lakes Res. 1994, 20, 625642.

(23) Liang, X.; Tian, C.; Zong, Z.; Wang, X.; Jiang, W.; Chen, Y.; Ma, J.; Luo, Y.; Li, J.; Zhang, G. Flux and source-sink relationship of heavy metals and arsenic in the Bohai Sea, China. Environ. Pollut. 2018, 242, 1353-1361.

(24) Zhen, X.; Tang, J.; Liu, L.; Wang, X.; Li, Y.; Xie, Z. From headwaters to estuary: Distribution and fate of halogenated flame retardants (HFRs) in a river basin near the largest HFR manufacturing base in China. Sci. Total Environ. 2018, 621, 13701377.

(25) Pan, X.; Tang, J.; Li, J.; Zhong, G.; Chen, Y.; Zhang, G. Polybrominated diphenyl ethers (PBDEs) in the riverine and marine sediments of the Laizhou Bay area, North China. Journal of Environmental Monitoring 2011, 13, 886-893.

(26) Oros, D. R.; Hoover, D.; Rodigari, F.; Crane, D.; Sericano, J. Levels and distribution of polybrominated diphenyl ethers in water, surface sediments, and bivalves from the San Francisco Estuary. Environ. Sci. Technol. 2005, 39, 33-41.

(27) Venier, M.; Dove, A.; Romanak, K.; Backus, S.; Hites, R. Flame retardants and legacy chemicals in Great Lakes' water. Environ. Sci. Technol. 2014, 48, 9563-9572.

(28) Huang, G. P. The Spatial-temporal Vairations of Dissolved Black Carbon in the the Bohai Sea Water, China and the River Fluxes. Ph.D. Dissertation, Chinese Academy of Sciences, Yantai Institute of Coastal Zone Research, 2016.

(29) Braekevelt, E.; Tittlemier, S. A.; Tomy, G. T. Direct measurement of octanol-water partition coefficients of some environmentally relevant brominated diphenyl ether congeners. Chemosphere 2003, 51, 563-567.

(30) Tittlemier, S. A.; Halldorson, T.; Stern, G. A.; Tomy, G. T. Vapor pressures, aqueous solubilities, and Henry's law constants of some brominated flame retardants. Environ. Toxicol. Chem. 2002, 21, $1804-1810$. 
(31) Covaci, A.; Harrad, S.; Abdallah, M. A.-E.; Ali, N.; Law, R. J.; Herzke, D.; de Wit, C. A. Novel brominated flame retardants: a review of their analysis, environmental fate and behaviour. Environ. Int. 2011, 37, 532-556.

(32) Liu, D.; Lin, T.; Shen, K.; Li, J.; Yu, Z.; Zhang, G. Occurrence and Concentrations of Halogenated Flame Retardants in the Atmospheric Fine Particles in Chinese Cities. Environ. Sci. Technol. 2016, 50, 9846-9854.

(33) Chen, Y.; Li, J.; Tan, Q. Trends of production, consumption and environmental emissions of Decabromodiphenyl ether in mainland China. Environ. Pollut. 2020, 260, 114022.

(34) Xiong, J.; Li, G.; An, T.; Zhang, C.; Wei, C. Emission patterns and risk assessment of polybrominated diphenyl ethers and bromophenols in water and sediments from the Beijiang River, South China. Environ. Pollut. 2016, 219, 596-603.

(35) He, M.-J.; Li, Q.; Zhao, J.-Y.; Wang, D.-X. Concentrations and Partitioning of Halogenated Flame Retardants in Industrial Water of Dongjiang River. Environ. Sci. 2016, 37, 2539-2546.

(36) Mahmood, A.; Malik, R. N.; Li, J.; Zhang, G. Distribution, congener profile, and risk of polybrominated diphenyl ethers and dechlorane plus in water and sediment from two tributaries of the Chenab River, Pakistan. Arch. Environ. Contam. Toxicol. 2015, 68, 8391.

(37) Barón, E.; Santín, G.; Eljarrat, E.; Barceló, D. Occurrence of classic and emerging halogenated flame retardants in sediment and sludge from Ebro and Llobregat river basins (Spain). J. Hazard. Mater. 2014, 265, 288-295.

(38) Chen, S.-J.; Feng, A.-H.; He, M.-J.; Chen, M.-Y.; Luo, X.-J.; Mai, B.-X. Current levels and composition profiles of PBDEs and alternative flame retardants in surface sediments from the Pearl River Delta, southern China: Comparison with historical data. Sci. Total Environ. 2013, 444, 205-211.

(39) Zhu, B.; Lam, J. C. W.; Yang, S.; Lam, P. K. S. Conventional and emerging halogenated flame retardants (HFRs) in sediment of Yangtze River Delta (YRD) region, East China. Chemosphere 2013, 93, 555-560.

(40) Ju, T.; Ge, W.; Jiang, T.; Chai, C. Polybrominated diphenyl ethers in dissolved and suspended phases of seawater and in surface sediment from Jiaozhou Bay, North China. Sci. Total Environ. 2016, 557-558, 571-578.

(41) Cetin, B.; Odabasi, M. Air-Water Exchange and Dry Deposition of Polybrominated Diphenyl Ethers at a Coastal Site in Izmir Bay, Turkey. Environ. Sci. Technol. 2007, 41, 785-791.

(42) Ni, K.; Lu, Y.; Wang, T.; Shi, Y.; Kannan, K.; Xu, L.; Li, Q.; Liu, S. Polybrominated diphenyl ethers (PBDEs) in China: policies and recommendations for sound management of plastics from electronic wastes. J. Environ. Manage. 2013, 115, 114-123.

(43) Pan, X.; Tang, J.; Li, J.; Guo, Z.; Zhang, G. Levels and distributions of PBDEs and PCBs in sediments of the Bohai Sea, North China. Journal of Environmental Monitoring 2010, 12, 12341241.

(44) Tokarz, J. A.; Ahn, M.-Y.; Leng, J.; Filley, T. R.; Nies, L. Reductive Debromination of Polybrominated Diphenyl Ethers in Anaerobic Sediment and a Biomimetic System. Environ. Sci. Technol. 2008, 42, 1157-1164.

(45) Shandong Haiwang Chemical Co. Ltd.. https://sdhwchem. 51pla.com/about.htm (accessed on November 12, 2020).

(46) Shouguang Weidong Chemical Industry Co. Ltd.. http://www. wdchem.com/ (accessed on November 12, 2020).

(47) Qiao, L.; Zheng, X.-B.; Yan, X.; Wang, M.-H.; Zheng, J.; Chen, S.-J.; Yang, Z.-Y.; Mai, B.-X. Brominated flame retardant (BFRs) and Dechlorane Plus (DP) in paired human serum and segmented hair. Ecotoxicol. Environ. Saf. 2018, 147, 803-808.

(48) Lin, Y.; Qiu, X.; Zhao, Y.; Ma, J.; Yang, Q.; Zhu, T. Polybromobenzene pollutants in the atmosphere of North China: levels, distribution, and sources. Environ. Sci. Technol. 2013, 47, 12761-12767.

(49) Xie, Z.; Möller, A.; Ahrens, L.; Sturm, R.; Ebinghaus, R. Brominated flame retardants in seawater and atmosphere of the
Atlantic and the Southern Ocean. Environ. Sci. Technol. 2011, 45, $1820-1826$

(50) Möller, A.; Xie, Z.; Cai, M.; Sturm, R.; Ebinghaus, R. Brominated flame retardants and dechlorane plus in the marine atmosphere from Southeast Asia toward Antarctica. Environ. Sci. Technol. 2012, 46, 3141-3148.

(51) Lv, M.; Luan, X.; Liao, C.; Wang, D.; Liu, D.; Zhang, G.; Jiang, G.; Chen, L. Human impacts on polycyclic aromatic hydrocarbon distribution in Chinese intertidal zones. Nat. Sustain. 2020, 3, 878884.

(52) Chandra Yadav, I.; Devi, N. L.; Li, J.; Zhang, G. Examining the role of total organic carbon and black carbon in the fate of legacy persistent organic pollutants (POPs) in indoor dust from Nepal: Implication on human health. Ecotoxicol. Environ. Saf. 2019, 175, $225-235$.

(53) Wang, H.; Wang, A.; Bi, N.; Zeng, X.; Xiao, H. Seasonal distribution of suspended sediment in the Bohai Sea, China. Cont. Shelf Res. 2014, 90, 17-32.

(54) Xiong, P.; Yan, X.; Zhu, Q.; Qu, G.; Shi, J.; Liao, C.; Jiang, G. A Review of Environmental Occurrence, Fate, and Toxicity of Novel Brominated Flame Retardants. Environ. Sci. Technol. 2019, 53, 13551-13569.

(55) Vorkamp, K.; Rigét, F. F. A review of new and current-use contaminants in the Arctic environment: evidence of long-range transport and indications of bioaccumulation. Chemosphere 2014, 111, $379-395$.

(56) Wang, G.; Peng, J.; Xu, X.; Zhang, D.; Li, X. Polybrominated diphenyl ethers in sediments from the Southern Yellow Sea: Concentration, composition profile, source identification and mass inventory. Chemosphere 2016, 144, 2097-2105.

(57) Zhu, B.; Lai, N. L. S.; Wai, T.-C.; Chan, L. L.; Lam, J. C. W.; Lam, P. K. S. Changes of accumulation profiles from PBDEs to brominated and chlorinated alternatives in marine mammals from the South China Sea. Environ. Int. 2014, 66, 65-70.

(58) Bezares-Cruz, J.; Jafvert, C. T.; Hua, I. Solar Photodecomposition of Decabromodiphenyl Ether: Products and Quantum Yield. Environ. Sci. Technol. 2004, 38, 4149-4156.

(59) UNEP COP and POPRC Decisions on BDEs. http://chm. pops.int/Implementation/IndustrialPOPs/BDEs/Decisions/tabid/ 5372/Default.aspx (accessed on November 22, 2020).

(60) Schenker, U.; Soltermann, F.; Scheringer, M.; Hungerb Uhler, K. Modeling the Environmental Fate of Polybrominated Diphenyl Ethers (PBDEs): The Importance of Photolysis for the Formation of Lighter PBDEs. Environ. Sci. Technol. 2008, 42, 9244-9249.

(61) Qiao, S.; Shi, X.; Wang, G.; Zhou, L.; Hu, B.; Hu, L.; Yang, G.; Liu, Y.; Yao, Z.; Liu, S. Sediment accumulation and budget in the Bohai Sea, Yellow Sea and East China Sea. Mar. Geol. 2017, 390, 270-281.

(62) Wania, F.; Dugani, C. B. Assessing the long-range transport potential of polybrominated diphenyl ethers: a comparison of four multimedia models. Environ. Toxicol. Chem. 2003, 22, 1252-1261. 